\title{
Dyslexia and Specific Learning Disorders: New International Diagnostic Criteria
}

\author{
Donatella Rita Petretto* and Carmelo Masala
}

Department of Education, Psychology, Philosophy University of Cagliari, Cagliari, Italy

*Corresponding author: Donatella Rita Petretto, Department of Education, Psychology, Philosophy University of Cagliari, Cagliari, Italy, Phone: 070-6757501; E-mail: drpetretto@unica.it

Received date: Sep 09, 2017; Accepted date: Oct 13, 2017; Published date: Oct 19, 2017

Citation: Petretto DR, Masala C (2017) Dyslexia and Specific Learning Disorders: New International Diagnostic Criteria. J Child Dev Disord. Vol 3. No 4: 19.

Copyright: (C 2017 Petretto DR, et al. This is an open-access article distributed under the terms of the Creative Commons Attribution License, which permits unrestricted use, distribution, and reproduction in any medium, provided the original author and source are credited.

\section{Abstract}

Dyslexia is the most studied and the most known learning disorder in the world but there is only a relative agreement on the definition and on the diagnostic criteria used in clinical and research fields. Dyslexia refers mainly to the difficulties in learning to read and, even if it is generally diagnosed in the first years of schooling, it can have different clinical manifestations in different phases of life and it can also influence different dominions of life. In this editorial we will describe and analyze some recent findings in this field, also deriving from the change of diagnostic criteria proposed in 2013 by the American Psychiatric Association in DSM-5 that has led to an increase in the number of students that meet diagnostic criteria and that has led to an increase of the level of the heterogeneity of their functional profiles. Then, we will discuss some issues for future researches mainly in the field of psychometric assessment, neuropsychological assessment and specific interventions.

Keywords: Dyslexia; Learning disabilities; Low achievement criterion; Discrepancy criterion; Diagnosis; Neurodevelopmental disorder; Dsm-5

\section{Introduction}

Dyslexia is the most studied and the most known learning disorder in the world, but after more than 120 years from it first description by Pringle Morgan [1], there is only a relative agreement on the definition and on the diagnostic criteria used in clinical and research fields [2-4]. Dyslexia refers mainly to the difficulties in learning to read and, even if it is generally diagnosed in the first years of schooling (the end of the second year of the primary school), it can have different clinical manifestations in different phases of life and it can also influence different dominions of life [5-7]. It is estimated that about $5 \%-15 \%$ of students are likely to have a reading disorders, with different estimations according to the specific diagnostic criteria used [7,8]. In 1963 Kirk defined dyslexia as a kind of learning disability and defined learning disabilities as "an unexpected difficulty in learning one or more of one instrumental school abilities" [9]. Since this seminal work of Kirk [9-11], the idea of "an unexpected difficulty" has influenced research and clinical field, with a double interpretation of the idea of "unexpected difficulty", both interpretations are related to the "principle of discrepancy" [12]: the first interpretation is related to a discrepancy between the level of general abilities (mainly reasoning abilities) and specific learning abilities (the so called "discrepancy criterion"); the second one is related to the discrepancy between the level of achievement in specific instrumental school abilities and the level of schooling (named "low achievement criterion") [13]. In previous international diagnostic criteria (like these from DSM-IV [14] and ICD-10 [15], the two worldwide used international diagnostic classifications), the diagnosis of dyslexia was based on the "principle of discrepancy", the two criteria described above.

\section{New Diagnostic Criteria in DSM-5}

Now we are in a different phase of the study of this disorder: in 2013, after years of debates on this topic, in DSM-5 the American Psychiatric Association has modified international diagnostic criteria for learning disabilities [16-18]. There are several fundamental changes in the newly proposed diagnostic criteria: the elimination of "Discrepancy Criterion", the reference to "Response to intervention approach" and a new view by which learning disorders are seen as a group of disorders, within the Neurodevelopmental disorders group [16]. The use of the term "dyslexia" is now suggested only in the clinical field, while the adopted terminology is "Specific learning disorder with impairment in [...a specific academic ability]". "Specific learning disorder" is a single overarching category that comprises different learning disorders. For reading disorders, there is a specification of which abilities related to reading are partially or totally compromised (word reading accuracy, reading rate or accuracy and/or reading comprehension) [16]. The diagnostic criteria used for specific learning disorders are four: criterion a) the persistency of the symptoms for at least 6 months, despite specific interventions; criterion b) the impairment of single or more abilities, with negative effects on school achievement; criterion c) the onset in a school-age, even if the disorder 
could fully manifest later; criterion d) last but not least, there are different exclusion criteria. The first exclusion criterion refers to absence of intellectual disability. The second refers to the exclusion of a fragmentary and inadequate instruction. The third refers to linguistic proficiency in the language used for academic instruction. The fourth refers to absence of sensory problems high enough to justify the learning difficulties (visual and auditory sensory problems) $[16,17,19]$.

With reference to the first diagnostic criterion there is a debate about how to define specific interventions: the methodology "Response to intervention" (RTI) is a well-studied approach based on three tiers of intervention, aiming to create personalized and individualized support for students who struggle to learn. There is a broad debate about the use of RTI in diagnostic process for learning disability, and even before the start of the diagnostic process, with agreement from some authors and with the reference to RTI also in some national laws on learning disabilities [18], but by now there are economic, ethical and research issues to be faced before using it in all schools [17-20]. So an alternative way is to consider as specific interventions every "extra help" at school or at home or any kind of modification in teaching methods, taking into account the student's difficulties in learning [19]. According to Tannock [19], "the teacher or the parents must confirm that some kind of intervention/instruction for the learning difficulties was tried but the symptoms persist". But in our opinion, it is very difficult to demonstrate and quantify this kind of "specific intervention" and perhaps it could be useful to operationalise it better and in a more agreed way. The second diagnostic criteria refers to the specific affected academic skill (one or more than one), that must be substantially and quantifiably below those expected, based on the chronological age, and it influences negatively academic achievement, or occupational performance, or activities of daily life. With reference to the impairment in a single or more abilities, from a psychometric point of view the cut-off that is to be used is one and an half deviation standard below the expected mean in each single evaluated ability (or even one standard deviation in some cases, or under the $5^{\text {th }}$ percentile for some measure) [18]. With reference to the age of onset, there is an agreed awareness that the clinical manifestations of learning disorders can change during the individual's life and that they are a lifelong condition [6]. Generally they are discovered in the first years of schooling, but it is also possible that they could be discovered later in the individual's schooling history. In order to take into account the clinical manifestations in different phases of life, there is a clear reference to the schooling history and the clinical history, to the integrated use of standardized tests and the documented history of learning difficulties, most of all for individuals aged 17 and older, where the use of standardized tests could not be valid, sensible and specific enough to describe the quality and the quantity of the learning disorders [16]. Some Years ago, Uta Frith, one of the most known scientists in the field, stated "diagnosis based on behavioural criteria will always be problematic, as behavior is strongly influenced by comorbidity, motivation, age, and ability" and "Adults with dyslexia and adults with autism who show good compensation can sail through standard diagnostic tests. Have they ceased to be dyslexic or autistic? Of course not. They themselves tell us about their persisting problems, and we can reveal these problems with more subtle tests. We now know that dyslexics read well at a cost of time and effort" [6]. It is very important to take into account these different aspects in the diagnostic process. An important aspect is the explicit reference to primary and secondary instrumental academic abilities, the first mainly compromised and influenced in the first years of schooling and the second more influenced in the other periods of schooling, also in university and in job experiences. Regarding reading, primary academic abilities are described as inaccurate, slow or effortful word reading (for example frequent errors in single words reading tasks, the tendency to complete the word starting from the first syllable or the first stem, or difficulty sounding out a word); while secondary academic abilities are related to the understanding and the elaboration of the meaning of what is read (for example difficulty in understanding the phrase or the sentences read, in making inference starting from what is read, in making a deeper analysis and in understanding of a text read, and in making a network of knowledge starting from the text read). But secondary academic abilities refer also to other aspects of reading, like the possibility to access in a deeper way the content of a text after reading it, or the possibility to elaborate, study and remember what is read. According to the diagnostic criteria proposed in DSM-5, clinicians and researchers have to estimate the level of severity of the learning disorders in a way that resembles the definition of disability as a process which is not merely the result of the features of the individual, but instead the consequence of the relationship between the individual and the environment [21-22]. This new definition of severity is based on the level of support needed and the effects of the support received on the possibility to complete all the required tasks efficiently in school, at home, or at the workplace (mild level of support, moderate level of support, high level of support) [16]. Scanlon [23] stated that the risk is that instead of evaluating the support needed, the level of support could be used to define the level of severity of the disorder itself, like in previous classifications of mental retardation (or the now so-called "intellectual disability") [23]. And again, according to Scanlon [23] there is another more general negative aspect related to the evaluation of the level of support needed: there is only a reference to the capacity to complete task and not to the personal development, including development sufficient enough to achieve independence from any support.

But in a positive view, in this new phase of the study of learning disorders, there is a clear reference to the environmental demands and to the relationship among environmental demands and the individual's capacities and his/her academic skills. There is a growing interest in the social model of learning disorders, according to which the real magnitude of difficulties that people with learning disorders can experience depends on the relationship with the environment and on the role that the social environment recognized to the reading ability $[21-22,24]$. 


\section{Heterogeneity of Cognitive and Neuropsychological Profiles in Individuals with Learning Disorders}

There are two main consequences of the change in the diagnostic criteria proposed by the American Psychiatric Association: the first one is the increase of number of people who meet the diagnostic criteria and the second one is the relative heterogeneity of the functional profile of people who meet the diagnostic criteria [17,19,25-27].

Most of all, the elimination of the "discrepancy criterion" and the reference only to the "low achievement criterion" led to a high level of heterogeneity also in general reasoning abilities. The exclusion criterion about intellectual disabilities makes it possible for individuals with learning disabilities to have high, average or below average reasoning abilities, as measured by psychometric assessment of intelligence. It is so theoretically possible, for example, to have an Intelligence Quotient $\geq 70$ (also taking into account the standard errors of measuring) and a Reading Quotient <85 (in the countries where this is admitted). The consequence is a wide range of possibilities in regard to intellectual and correlated abilities.

So, even if the Intelligence Quotient is no central anymore in the diagnosis of dyslexia, according to the elimination of the "discrepancy criterion", the psychometric assessment of intelligence derived from the professional use of standardized intelligence instruments and a deeper assessment of neuropsychological profile of people with learning disorders, is still recommended [28-36], even with an open debate [37]. Recent findings in the study of intellective and neuropsychological assessment of individuals with learning disorders describe impairments on different cognitive and neuropsychological functions related to learning, like working memory, long term memory (implicit memory and explicit memory), attention (selective and sustained), linguistic abilities, praxic abilities, visuospatial abilities, problem solving abilities, executive abilities [38-45] and other cognitive functions more directly related to the learning of reading, as phonological abilities $[46,47]$. Executive functions and their relationship with learning is nowadays a key point in this field, mainly during adolescence and adult life, where they seem to have a crucial role in learning difficulties [42,48-52]. This brief overview of research findings highlights both the heterogeneity of the functional profiles of individuals with learning disorders and the need to study the functional profile of each individual in a deeper way. The most important aim of psychometric assessment and neuropsychological assessment is to help clinicians in a deeper understanding of the heterogeneity of the functional profiles of people with specific learning disorders and to help them in defining interventions [53]. The main aim of any intervention is to guarantee the right to study, the right to work and the right to well-being in learning context for people with learning disorder, and to support people with learning disorders in developing their potentials, interests and well-being [26-27].

\section{Conclusion}

We are now in a new phase of the study of specific learning disorders, according to the change of diagnostic criteria and to the awareness of the existing huge heterogeneity in individuals with learning disorders (and also in the same individual, in different phases of his/her life). In our opinion, the study of specific learning disorders is in an advanced step, but there are more steps to be done, mainly in the description of functional profiles and in the study of core symptoms. What about next steps? According to some authors, the greatest challenge for a common definition of Learning Disorders has not been reached yet $[4,23,54]$, and this is still an open challenge. The diagnostic assessment is an important step, but not the only one, in a path that goes from difficulties in school, or in university, or at work, to the definition of any kind of intervention. Clinical and research data and the new diagnostic criteria for learning disability highlight three different foci of attention in the definition of any kind of intervention: the specific phase in the life of the individual, the specific primary and secondary instrumental academic abilities involved, and the specific cognitive and neuropsychological functions involved. The relationship between these three foci and specific strategies (or instruments) for intervention is likely to be the focus of increased research interest in the near future.

Moreover, a question emerges: "Is it still an unexpected difficulty in learning?" as proposed by Kirk in 1963 [9]? In our opinion, the idea of "an unexpected difficulty" is superseded by the research findings about the relationship between different abilities correlated to learning disorders, about comorbidities among learning disorders themselves and among learning disorders and other neurodevelopmental disorders. Taking into account all these aspects, learning disorders do not seem any more as an "unexpected difficulty in learning". So, it is possible now to expect and to predict difficulty in learning in a group of students and individuals in different phases of life and it is possible to design specific intervention to support them in their learning path. According to Butterworth and Kovas [55], we believe that a better understanding of learning disorders could enhance the level of well-being not only for each student (or each individual) who struggle to learn but for all students (or all individuals) [44-45]. This way "can improve education for all" and can also improve respect for individual differences in different aspects of lives [44-45,55].

\section{Acknowledgments}

The Authors wish to thank all the individuals with learning difficulties, their families and all the teachers who collaborate everyday to their researches. The authors wish also to thank all the research staff, collaborators and students. This study is supported by DRP's personal research grant from the University of Cagliari. DRP and CM equally contributed to the design of the study, to the qualitative analysis of literature, drafted and revised the paper and have approved the final manuscript. The Authors are grateful to Dr. Andrea Domenico Petretto and to the Medical Students Ilaria Masala and Ioannis Kazantzis for English revision. 


\section{References}

1. Morgan P (1896) A case of congenital word blindness. Brit Med J 7: 1378.

2. Durrant JE (1994) A decade of research on learning disabilities: a report card on the state of the literature. J Learn Disabil disabilities 27: 25-33.

3. Williams JL, Miciak J, Mc Farland L, Wexler J (2016) Learning disability identification criteria and reporting in empirical research: a review of 2001-2013. Learn Disabil Res Pract 31: 221-229.

4. Grunke M, Cavendish W (2016) Learning disabilities around the globe: making sense of the heterogeneity of the different point of viewpoints. Learning Disabilities: a contemporary Journal 14: 1-8.

5. Shaywitz SE, Morris R, Shaywitz BA (2008) The education of dyslexic children from childhood to young adulthood. Annu Rev Psychol 59: 451-475.

6. Frith U (2013) Autism and Dyslexia: a glance over 25 years of research. Perspect Psychol Sci 8(6): 670-672.

7. Schulte-Korne G (2014) Specific learning disabilities- from DSMIV to DSM-5. Z Kinder Jugendpsychiatr Psychotherapy 42: 369-372.

8. Habib M, Giraud K (2013) Dyslexia. Handbook of Clinical Neurology 111: 229-235.

9. Kirk SA (1963) Behavioral diagnosis and remediation of learning disabilities. In Proceedings of the Conference on the Exploration Into Problems of the Perceptually Handicapped Child (pp. 1-7). Evanston, IL: Fund for the Perceptually Handicapped Child.

10. Kirk SA (1962) Educating exceptional children. Boston, Houghton Mifflin.

11. Kirk SA, Elkins J (1975) Characteristics of children enrolled in the child service demonstration centers. J Learn Disabil 8: 630-637.

12. Bateman B (1965) Learning Disabilities: an overview. Journal of School Psychology 3: 1-12.

13. Dombrowski SC, Kamphaus RW, Reynolds CR (2004) After the demise of the discrepancy: proposed learning disabilities diagnostic criteria. Professional Psychology: Research and Practice 4: 364-372.

14. American Psychiatric Association (1994) Diagnostic and statistical manual of mental disorders (4th edition). Washington DC, APA.

15. World Health Organization (1992). International statistical classification of diseases and related health problems: 10th revision (ICD-10). Geneva, Switzerland, WHO.

16. American Psychiatric Association (2013) Diagnostic and Statistical manual of mental disorders. Washington DC, APA.

17. Tannock R (2013) Rethinking ADHD and LD in DMS-5: proposed changes in diagnostic criteria. J Lear Dis 46: 5-25.

18. Cavendish W (2013) Identification of Learning disabilities: implications of Proposed DSM-5 criteria for school-based assessment. Journal of Learning Disabilities 46: 52-57.

19. Tannock R (2016) Provision of evidence-based intervention is not part of the DSM-5 diagnostic criteria for Specific Learning Disorder. Eur J Child and Adolescent Psychiatry 25: 209-210.
20. Dombrowski SC, Gischlar KL (2014) Ethical and empirical considerations in the identification of learning disabilities. J Applied School Psychology 30: 68-82.

21. Masala C, Petretto DR (2008a) From disablement to enablement: conceptual models of disability in the 20th century. Disability and Rehabilitation 30: 1233-44.

22. Masala C, Petretto DR (2008b) Psicologia dell'handicap e della riabilitazione: dal "hand in cap" alla partecipazione. Ed. Kappa, Roma.

23. Scanlon D (2013) Specific learning disability and its newest definition: which is comprehensive? And which is insufficient? J Learning Disabilities 46: 26-33.

24. Riddick B (2001) Dyslexia and inclusion: time for a social model of disability perspective? International Studies in Sociology of Education 11: 223-236.

25. Al-Yagon M, Cavendish W, Cornoldi C, Fawcett AJ, Grunke M, et al. (2013) The proposed changes for DSM-5 for SLD and ADHD: international perspectives. J Learn dis 46: 48-72.

26. Petretto DR, Piras P, Pistis I, Masala C (2017a) Disabilità, difficoltà di apprendimento ed ambiente: La psicologia della disabilità e la neuropsicologia quali basi per lo sviluppo di una "School for all"? in Faiferri M, Bartocci S, Pusceddu F (eds) (2017a) ILS Innovative learning spaces. List Laboratorio Internazionale Editoriale, ISBN 9788899854409, 2017a.

27. Petretto DR, Piras P, Pistis I, Masala C (2017b) Disability, learning difficulties and environment: Psychology of disability and Neuropsychology as basis for the development of a "School for all"? in Faiferri M, Bartocci S, Pusceddu F (eds) (2017b) ILS Innovative learning spaces. List Laboratorio Internazionale Editoriale, ISBN 9788899854393, 2017b.

28. Semrud-Clikeman M (2005) Neuropsychological Aspects for evaluating learning disabilities. Communication disorders Quarterly 26: 242-247.

29. Silver CH, Blackburn LB, Arffa S, Barth JT, Bush SS, et al. (2006) The importance of neuropsychological assessment for the evaluation of childhood learning disorders - NAN Policy and Planning Committee. Archives of Clinical Neuropsychology 21: 741-744.

30. Berninger VW, Raskind W, Richards T, Abbott R, Stock P (2008) A multidisciplinary approach to understanding developmental dyslexia within working-memory architecture: genotypes, phenotypes, brain and instruction. Developmental Neuropsychology 33: 707-744.

31. Silver $\mathrm{CH}$, Ruff RM, Iverson GL, Barth JT, Broshek DK, et al. AN Policy and Planning Committee (2008) Commentary - Learning Disabilities: the need for neuropsychological Evaluation. Archives of Clinical Neuropsychology 23: 217-219.

32. Fenwick WE, Kubas HA, Witzke JW, Fitzer KR, Miller DC, et al. (2015) Neuropsychological Profiles of written expression learning disabilities determined by concordance-discordance model criteria. Applied Neuropsychology: child 0: 1-114.

33. Miciak J, Taylor P, Deanton CA, Fletcher JM (2015) The effect of achievement test selection and identification of learning disabilities within a patterns of strengths and weakness framework. School Psychology Quarterly 30: 321-334.

34. Petretto DR, Piras P, Pistis I, Tradori E, Camboni MV, et al. (2016) Difficulties in reading, learning difficulties and neuropsychological profile on WISC-IV in Italian children. IEEE 
International symposium on Medical Measurement and Applications.

35. Giofrè D, Toffalini E, Altoè G, Cornoldi C (2017) Intelligence measures as diagnostic tools for children with specific learning disabilities. Intelligence 61: 140-145.

36. Schneider WJ, Kaufman AS (2017) Let's not do away with comprehensive cognitive assessments just yet. Archives of Clinical Neuropsychology 32: 8-20.

37. Fletcher JM, Miciak J (2017) Comprehensive Cognitive Assessments are not necessary for the identification and treatment of learning disabilities. Arch Clin Neuropsychol 32: 2-7.

38. Moll K, Gobel SM, Gooch D, Landerl K, Snowling MJ (2014) Cognitive risks factors for specific learning disorder: processing speed, and working memory. J Learn Disabil 1-10.

39. Mammarella IC, Cornoldi C (2014) An analysis of the criteria used to diagnose children with Nonverbal learning disability (NLD). Child Neuropsychol 20: 255-280.

40. Cornoldi C, Giofrè D, Orsini A, Pezzuti L (2015) Differences in the intellectual profile of children with intellectual vs learning disability. Res Dev Disabil 35: 2224-2230.

41. Giofrè D, Stoppa E, Ferioli P, Pezzuti L, Cornoldi C (2016) Forward and backward digit span difficulties in children with specific learning disorder. J Clin Exp Neuropsychol 38: 478-486.

42. Smith-Spark JH, Henry LA, Messer DJ, Edvardsdottir E, Ziecik AP (2016a) Executive functions in adults with developmental dyslexia. Res Dev Disabi 53: 323-341.

43. Liebel SW, Nelson JM (2017) Auditory and Visual Working memory functioning in college students with attention-deficit/ hyperactivity disorder and/or Learning Disabilities. Arch Clin Neuropsychol 7:1-12.

44. Petretto DR, Masala C (in press) L'intelligenza: L'intelligenza: tra psicologia clinica ed intervento. Edizioni Aracne, Roma.
45. Petretto DR, Bariffi F, Jimenez E, Volterra S, Masala C (in press), I Bisogni Educativi Speciali: il diritto all'istruzione in una prospettiva inclusiva. Edizioni Jovene, Napoli.

46. Saksida A, lannuzzi S, Bogliotti C, Chiaix $Y$, Demonet JF, et al. (2016) Phonological skills, visual attention span, and visual stress in developmental dyslexia. Dev Psychol 52: 1503-1516.

47. Szenkovits G, Darma Q, Darcy I, Ramus F (2016a) Exploring Dyslexic's phonological deficit II: phonological grammar. First language 1-22.

48. Smith-Spark JH, Fisk JE, Fawcett AJ, Nicolson RI (2003) Central executive impairments in adult dyslexics: evidence from phonological and visuospatial working memory performance. Eur J Cogn Psychol 15: 567-587.

49. Smith-Spark JH, Fawcett AJ, Nicolson RI, Fisk JE (2004) Dyslexic students have more everyday cognitive lapses. Memory 12: 174-182.

50. Smith-Spark JH, Ziecik AP, Sterling C (2016b) Time-based prospective memory in adults with developmental dyslexia. Res Dev Disabil 49-50: 34-46.

51. Grinblat N, Rosenblum S (2016) Why are they late? Timing abilities and executive control among students with learning disabilities. Res Dev Disabil 59: 105-114.

52. Alahmadi NA (2017) Cognitive control in children with learning disabilities: neuromarker for deficient executive function. Neuroreport 28: 638-644.

53. Mourea D, Waldie KE (2016) Developmental learning disorders: from generic interventions to individualized remediation. Front Psychol 6: 2053.

54. Venkatesan S (2017) Diagnostic decision tree for specific learning disability. Inter J Educ Psychol Res 6: 121-127.

55. Butterworth B, Kovas $Y$ (2013) Understanding neurocognitive developmental disorders can improve education for all. Science 340: 300 . 